\title{
Establishment of the Swedish Aeronautical Research Center (SARC)
}

Ingo Staack

The self-archived postprint version of this journal article is available at Linköping University Institutional Repository (DiVA):

http://urn.kb.se/resolve?urn=urn:nbn:se:liu:diva-160063

N.B.: When citing this work, cite the original publication.

Staack, I., (2019), Establishment of the Swedish Aeronautical Research Center (SARC), AIRCRAFT ENGINEERING AND AEROSPACE TECHNOLOGY, 91(6), 857-864. https://doi.org/10.1108/AEAT07-2018-0201

Original publication available at:

https://doi.org/10.1108/AEAT-07-2018-0201

Copyright: Emerald

http://www.emeraldinsight.com/ 


\section{Establishment of the Swedish Aeronautical Research Center}

\section{(SARC)}

\section{Abstract}

Purpose - The paper presents the newly founded Swedish Aeronautical Research Center (SARC), based on the triple helix theory to foster the seamless Swedish aerospace research interplay between academia, research organizations, and industry.

Design/methodology/approach - The paper is a Technical Paper, mainly relating and explaining sources and concepts for research planning and organization. Used concepts are the triple helix approach (for socio-economic effects), the role of academia and industry interplay for education, and the Technology Readiness Level (TRL) concept for strategic research planning. Focusing on the establishment of a graduate school, lessons learned from previous national research schools are also presented.

Findings - The paper gives an overview of and explains the interplay between politics, social welfare, and industrial R\&D needs with the academic viewpoint of aeronautical research and education. Shortcomings in both the use of TRL for research programme planning and the Swedish competence cluster system are identified and remedies suggested. The main findings are suggestions for future actions to be conducted by SARC in the fields of research and education.

Practical implications - The paper includes implications for the seamless interplay between academia, research organizations, and industry.

Originality/value - So far, no publication about the newly founded SARC has been made yet. It is unique in the way that it makes substantial use of national technical documents so that this information becomes available for non-Swedish speakers. Additionally, the perhaps unique system of industrial competence clusters is presented.

Keywords research and education, academia-industry interplay, graduate school, technology readiness level (TRL), triple helix

Paper type Technical paper 


\section{Introduction}

Aerospace is - alongside communication technologies -- bringing the world together. The result is a never before seen increase in travelling and worldwide flow of goods with positive social and economic effects but also significant negative environmental impacts. However, aerospace is not only "joining the world", but at the same time represents an international business with a worldwide supply chain for both civil and military systems that can act as a key driver of a country's growth and international competitiveness (Hartley, 2014). Sweden, with a population of ca. 10 million and a GDP of $\$ 601$ billion, is one of the smallest countries with an intact/complete (military) aviation industry including a broad national aviation research strategy to maintain the competitiveness and expertise of its main industrial actors. The largest industrial actors are Saab AB (aircraft and complete defence systems) and GKN (propulsion and jet engine technologies), formerly Volvo Flygmotor. Nowadays, the mature of technical systems, technology and operation results in a never before seen system/vehicle complexity hardly manageable by one country alone. This obviously has an influence on research and education, too. With the recent establishment of the Swedish Aeronautical Research Center (SARC) in June 2018 (SARC, 2018), these two topics -- research and education, among others -- are expected to be strengthened by a careful interplay conducted by SARC among industry, universities and government agencies, based on a concept of strategic research clusters. This paper presents two topics, each presenting future challenges facing the aerospace sector with the boundary condition of Sweden as a small country with limited resources and a strategic, complete expertise in aviation technologies:

part 1: TRL-based research and the slanted wave: research complexity and the need for academic collaboration

part 2: The establishment of SARC as a catalyst for collaboration in research and education

\section{SARC BACKGROUND: TRL-related Strategic Research Collaborations and the Triple Helix}

Research and education are both topics based upon and blossomed out by collaboration, the sharing of knowledge and information, communication, and discussion. It is also recognized that a very important reason for universities to have research -- rather than to place research solely at separate establishments -- is to provide a research overhead to education, which after all is the prime objective of universities (Fung et al., 2017). University-based education includes postgraduate students who are more directly involved in research projects and graduate or undergraduate students as indicated in Figure 1. With the presence of industrial research collaboration, university staff as well as students learn the application and relevance of different research topics, which leads towards a more relevant, better, and up-to-date education.

The SARC's vision is to be a national forum and contact for aeronautical research, to promote research continuity and to give input for a national long-term research strategy. Those topics foster a sound research overhead for education. 
Furthermore, it directly benefits the aeronautic industry, which is more short/medium-term focused and runs short on longterm, low TRL level research project financing.

Figure 1 The interaction between academia and industry including straddlers/industrial teachers and industrial PhD students (not shown: government agencies and society). (Krus, 2018)

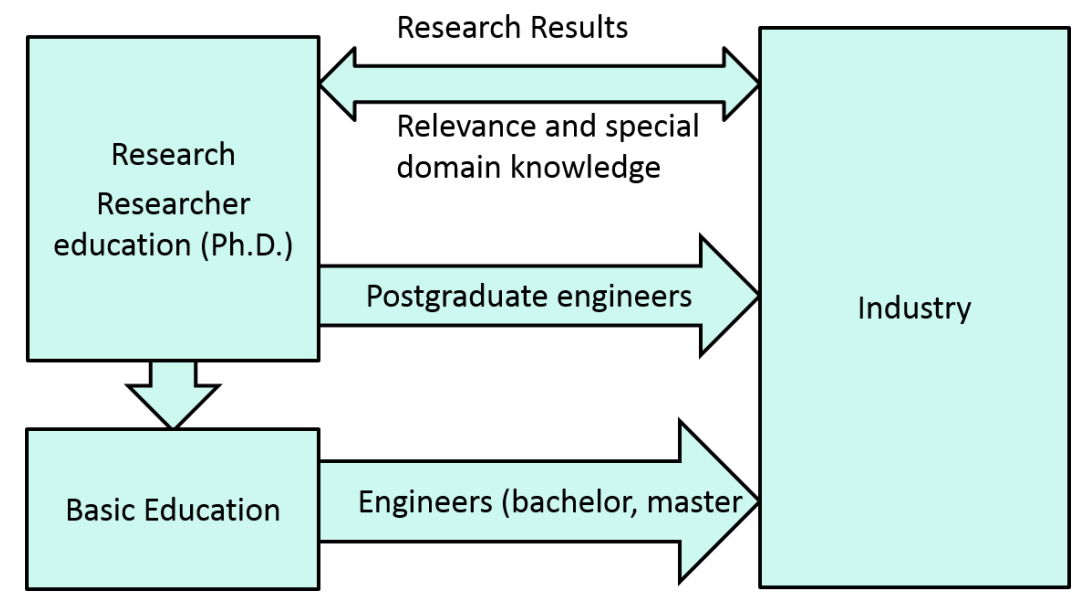

The aerospace industry is for various reasons prone to large, international consortia for research, product development, production and operation. There are many reasons for this trend: system complexity, high reliability demand, multi-domain characteristic, extremely long life-cycles, valuable products, scale effects (small number of produced products and fleet design) to name only a few. In addition, aeronautical products are often not only complex products but represent so-called System of Systems (SoS) (for a definition see (Maier, 1998)) which have to be dealt with in a different way, within both research and product development (Staack et al., 2018). The high risks to be taken, the high reliability requirements, the long lead times and extremely long life cycle times of aeronautical products/systems render the aerospace industry rather conservative - with some exceptions ${ }^{1}$. A useful measure introducing new technologies from an engineering/technical point of view, introduced by NASA for the space industry in the late 1990s, is the Technology Readiness Level (TRL) (NASA, 2007). The TRL index of a technology can be used as a rough estimate of:

- Cost needed to conduct the required actions to reach the next TRL level

- $\quad$ Time to market

- Risks taken

\footnotetext{
${ }^{1}$ Exceptions are usually start-ups/newcomers like SpaceX in the aerospace market with its vertical landing rockets, the UAV market with uncountable actors and the emerging electric flying taxi market with start-ups such as Lilium.
} 
- Uncertainty/lack of knowledge regarding the technology use/application and implications

While time-to-market shrinks with increasing $T R L$ level, the costs within each step expand. At very low $T R L$ the long-term development to be performed, the vast amount of money needed, and the uncertainty/absence of knowledge as to where and how to implement it (on which product and how) make it hard for (short/medium-term profit oriented) companies to motivate research at low TRL levels. On the other hand, high TRL level development within the aerospace sector requires large enterprises, workload and infrastructure (for manufacturing and testing/operation), that it is infeasible to be reached by universities.

With Sweden as an example, high-level TRL research is even too large and costly for most enterprises so that such research has to be conducted by bi-/multi-lateral (usually EU funded) projects such as Horizon 2020.

Figure 2 The slanted wave TRL-based technology spread on an example of civil (GKN) engine technologies.

Figure source (Olsson, 2018)

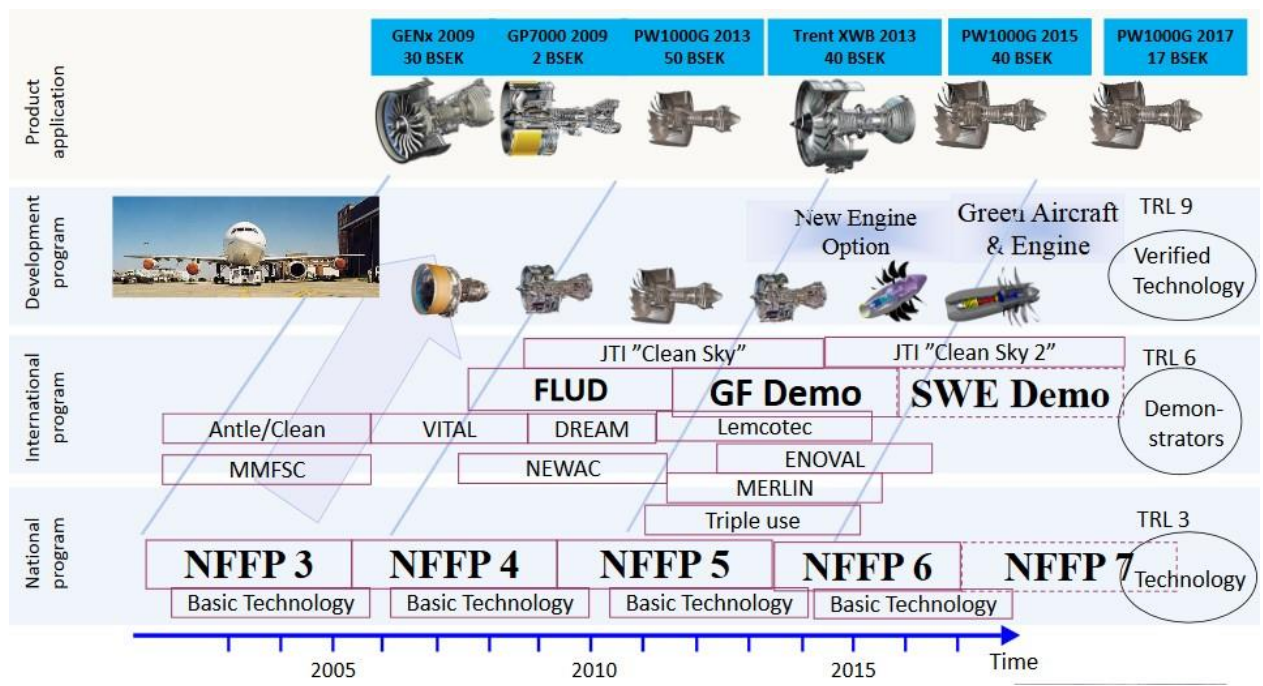

Figure 2 shows the so-called slanted wave behaviour of the technology maturing process indicated by the TRL level in the example of Swedish National Aeronautical Research Programs (NFFPs) (NFFP, 2018). Typical lead times between the national low TRL research until product on the market range between 10 and 20 years (Olsson, 2018). While Figure 2 shows only civil applications, the NFFP financed (low TRL level) research focuses on dual use (military and civil) or triple use (additional innovation/technology spread to other sectors) (Blom, 2018).

An important aspect of the research financing within the Strategic Innovation Programs (SIPS) financed by the Swedish Governmental Agency for Innovation Systems (VINNOVA) is socioeconomic effects (measures). For instance is the return on public investment in the C/D version Gripen programme beyond the 2.6-fold social return on public investment (Tillvaxtanalys, 2016). (Eliasson 2010) identified three main areas of the technology contribution of Sweden's aeronautic sector: 
- Technology transfer of a high TRL level / operational focused technologies: industry acting as a university, providing research, education and training to other firms and sectors

- Spill-overs to other domains such as software engineering, systems engineering, lightweight structures and medicine

- Maintaining of a (defence) industry capable of developing complete military aircraft combat systems and associated systems.

Sweden's military aviation industry capability is based upon spillover effects from the Gripen and its predecessors' projects, routines and systems engineering capabilities. This becomes apparent in the example of the pace of recent maiden flights with significant contributions from Saab AB: 20 th December 2017: Trainer Boeing T- $X^{2} ; 15^{\text {th }}$ June 2017: Gripen NG; 14 March 2018: GlobalEye Airborne Early Warning \& Control Aircraft (and on 26 $6^{\text {th }}$ September 2017 the civil Airbus A340 BLADE).

The above mention triple (or dual) use NFFP research approach should not be confused with the triple-helix approach by Henry Etzkowitz (Etzkowitz, 2008). The latter focuses on the interplay between universities, industry, and government within modern societies. Sweden, with a high educational level and a country of high innovation capacity seems made to match Etzkowitz's view. In the context of the SARC establishment, it is useful to have knowledge and understanding of the triple-helix axiom to be able to establish an as-good-as-possible collaboration of the research-centred part of the triple-helix including university research centres, science parks, technology transfer offices and incubators.

\section{More on Readiness Level Measures}

The use of the TRL as a metric of time-to-market and development cost as explained in the section above is a crude estimation that can easily be refined with limited effort. Various shortcomings and limitations of the TRL metric have to be kept in mind when using this index. The U.S. Government Accountability Office (GAO) lists the most prominent of them (GAO, 2016). Alongside the widely used and established TRL, other complementary indices with slightly different foci exist, such as:

- Manufacturing Readiness Level (MRL), a measure of the maturity of the manufacturing readiness of an object of technology related to $T R L$

- Business Readiness Level (BRL), a measure of the success or failure risk of a technology transition based on business considerations (circumstances)

\footnotetext{
${ }^{2}$ With a significant work share and system responsibility performed by Saab.
} 
- Integration Readiness Level (IRL), a measure of the interfacing of compatible interactions of different technologies and the maturity of integration between them

- System Readiness Level (SRL), a measure of the "individual TRLs in a system and their subsequent integration points with other technologies, the Integration Readiness Level (IRL)." (Sauser et al., 2006)

Figure 3 shows the difference between product-focused development phases (top) and technology-related TRL evolution (bottom). But not only technology and product development phases' foci differ. (Sauser et al., 2006) show that a technologyindividual TRL assessment (also denoted as a TRA) has certain shortcomings when applied to a "...system context, which may involve interplay between multiple technologies" that can be overcome by extending the assessment by means of some of the above named maturity indexes. These concerns are highly relevant for most aerospace applications, which often not only represent complex systems with a number of different domains and (new, unproven) technologies but may represent so-called SoSs that suffer or benefit even more strongly from the interplay between the entities (component or systems).

Figure 3 The parallel but different phased phases of product development and technology evolution alongside the TRL scale. Adapted from (Sauser et al., 2006)

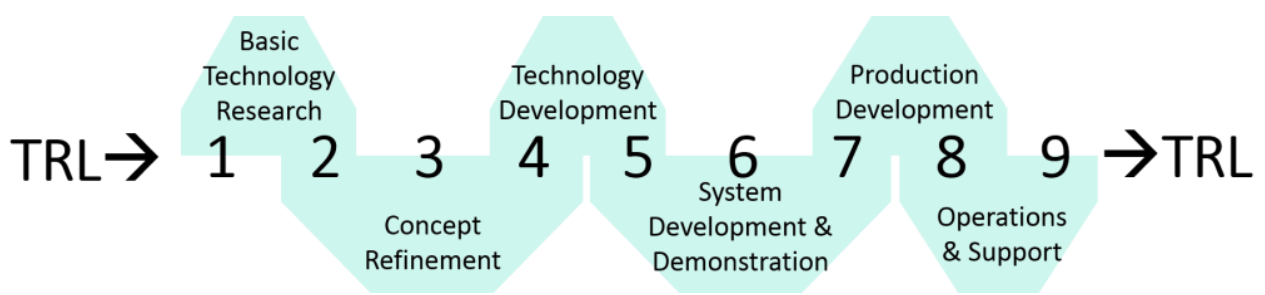

Consequently, the TRL-based research assessment is applicable to rough estimations (such as shown in Figure 2) but for detailed research or product development planning, more complex assessment criteria have to be applied.

Focusing on SoS engineering, system- (SRL) or integration- (IRL) focused methods might be more relevant than the $T R L$ index. The $I R L$ addresses three stages of integration maturity that have to be completed until the integration of a new technology can be assessed as proven: semantic, syntactic, and pragmatic (Sauser et al., 2009). Each of these topics consists of tree subsets, leading to nine steps in total, similar to the TRL index. The use of IRL enables the identification of integration maturity risks or incompatibility at very early stages on the semantic levels 1-3 (comparable to TRL 1-3). Higher $I R L$ levels can therefore be considered unnecessary if the focus is on conceptual (SoS) design only.

To conclude, it can be said that the TRL index is a reasonable and sufficient measure with respect to the SARC stakeholder needs -- research-focused project and high-level research management on mainly low (up to medium-low) TRL levels. However, it falls short for the industrial aspects of product/system development with its slightly different foci. A more complex approach (e.g. using IRL and similar indexes mentioned above) should therefore be considered to attain a good 
match between the academic research and the industries R\&D needs (and timelines) for future products. This topic seems especially important for Saab's military branch with a product portfolio of individual customer-adapted (defence) SoSs with high integrational risks.

\section{ESTABLISHMENT OF THE SWEDISH AERONAUTICAL RESEARCH CENTER (SARC)}

The Swedish Aeronautical Research Center (SARC) was inaugurated in 2018 at Linköping University (LiU) and serves as the host after several years of planning activities (SARC, 2018). Founding members are LiU and Chalmers University of Technology (Chalmers) only, but a dialogue is maintained with several academic players within aeronautics to shape SARC into a national entity. Expectations of SARC are high and differ slightly between the various stakeholders. Three-four ${ }^{3}$ main areas of activity have been identified:

- Research collaborations and alliances (national)

- International research collaborations

- Education of graduate (PhD academy) and undergraduate students

\section{Motivation for the Centre's Establishment}

As mentioned earlier, the SARC's stakeholders have slightly different motives but all have the main reasons for its establishment in common. The central point is to ensure and enhance the competitiveness of the Swedish aeronautical sector, which inevitably includes both industry and academia (see Figure 1 and Chapter 2). One relevant NFFP socioeconomic effect measure is the education of graduate students (PhDs), who to a large extent continue within the Swedish aviation industry after achieving the doctoral diploma (Åström et al., 2008). From the centre's funders' point of view (the Swedish Strategic Innovation Programme for Aeronautics (INNOVAIR, 2018) and VINNOVA), SARC should act for the following purposes (Blom, 2018):

- Structure and further improve the academic system in aeronautics and its relations to the other actors in the innovation system

- Guarantee long-term supply of skilled work force within prioritized technical fields of relevance for aeronautics

${ }^{3}$ Depending on the way of counting sub-graduate and post-graduate as one or two topics. 
- Guarantee long-term (low-level TRL) research of national/international (socio-) interests such as e.g. "green flight" for the national zero $\mathrm{CO}_{2}$ transportation target ${ }^{4}$

- Act as a lobby group for academic/aeronautical interests

- Strengthen the national university/agency conducted research by better alignment an closer collaboration (instead of segregation and competition)

All SARC research should contribute to lower environmental impact and improve social welfare by contributing to attain the European Commission goals (ACARE, 2011).

\section{SARC-Industry Collaboration}

The dialogue between Industry and academia should be strengthened by a tight integration of the competence clusters that were established at GKN and Saab together within the NFFP/INNOVAIR programme in 2014. Each cluster -- represented by a responsible (industrial) cluster lead (Swedish: klusterledare) -- represents one key technology of the company. Table 1 lists these 15 strategic technology clusters.

Table 1 European and US city-pairs selected for this investigation.

\begin{tabular}{ll}
\hline \hline Saab AB & GKN \\
\hline Avionic Platform Technology & \\
Operation and Maintenance & Engine Systems \& Installation \\
Aeronautical Engineering & Turbomachinery \\
HMI and Decision Support & Value Driven Development \\
Concept Methods \& System of Systems Methods & Advanced Materials (Metallic) \\
Cooperating Systems & Production Systems \& Processing \\
Sensors - System \& Functions & Composite Components \\
Structures \& Manufacturing Technology & Lifting \\
\hline \hline
\end{tabular}

Within NFFP, an education programme was offered for the cluster leads. In addition to seminar series, workshops, and courses in R\&D and academic processes, the focus had been put on a detailed insight into the various clusters' topics to

${ }^{4}$ The year 2020 climate targets set by the Swedish Government, see (Naturvardsverket, 2017). 
create an active, closely-collaborating network among the cluster leads. Figure 4 shows the comprehensive anticipated interactions between universities, research agencies and industries as an effect-chain from the first idea to research financing to industrial realization, conducted by the cluster lead (Alfredson and Jouannet, 2017). According to Vallhagen (2016), based on the analysis of selected (international) research projects with contributions from GKN, the following targets had been reached with the cluster setup already in 2016:

- Enhanced holistic project lead and better inter-project organization (focus alignment, synergy effects, collaboration)

- Exchange of experiences (inner/inter-enterprise) during the cluster lead training programme

- Finding of synergy effects and better aligned research of high industrial relevance

Early cluster lead activities focused mainly on industrial needs. While it worked out well for the industry (as shown by Vallhagen (2016)), no such tightly interconnected network existed on the academic side. Instead, collaboration and information exchange was arranged by extended use of so-called straddlers (Swedish: gränsgångare), people who are employed part-time in industry and academia, enabling among other things an active engagement at university research centres, and contact with PhD students and undergraduate student projects. The less strictly controlled academic environment made it easier for these people to spend more time on academic publications and enabled more flexibility and collaboration with international researchers (Vallhagen, 2016). This system worked well on individual/group level, but a central administration and inter-project/disciplinary and strategic, national long-term perspective from an academic viewpoint were lacking. This lack of an academic counterpart to the well-working (industrial) cluster leads will be taken up by SARC in the future.

Figure 4 The interplay of academia and industry with the help of the cluster lead acting as a central hub.

\section{Adapted from (Alfredson and Jouannet, 2017)}

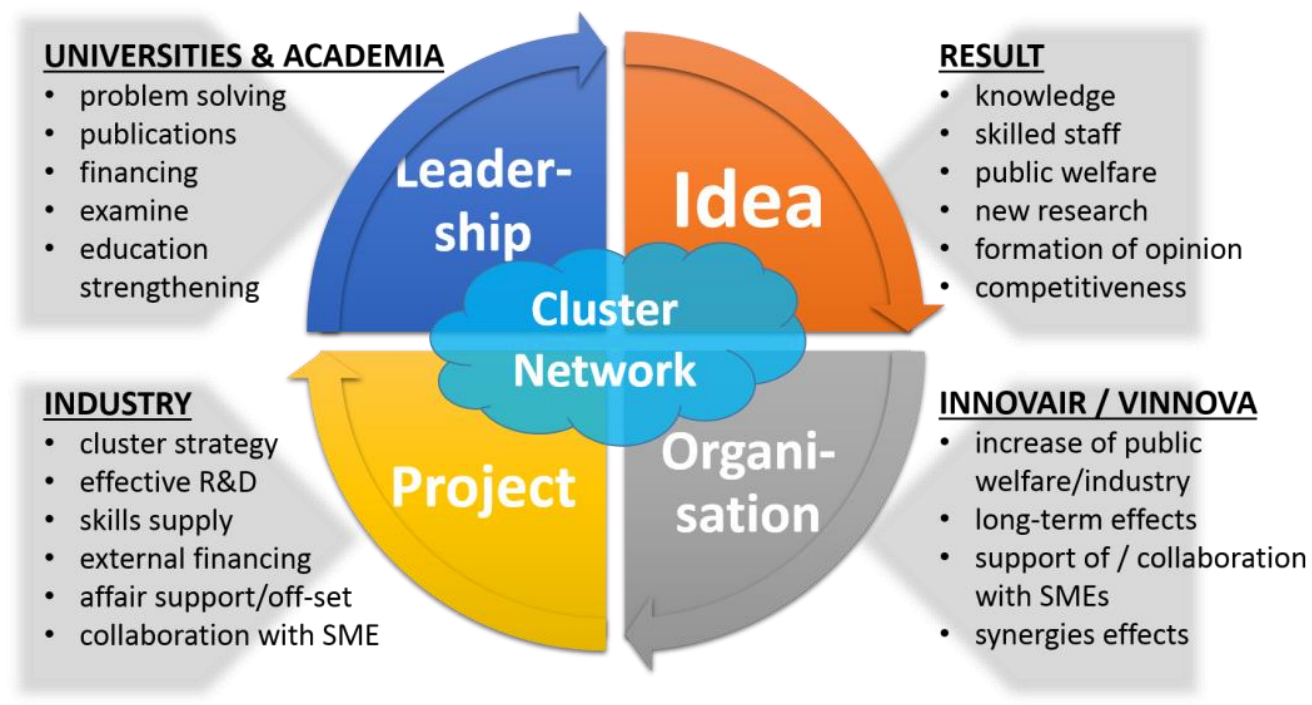




\section{SARC Research Academy}

One important topic in the industry human resource supply is graduate engineers (see Figure 1). In order to render aeronautical engineering more attractive, enhance the quality, and increase the proportion of foreign PhDs with doctorates from Sweden who stay in the country, SARC will build up a national aeronautical PhD academy. Approximately half of the SARC budget is designated to drive this graduate school.

The SARC PhD academy picks up lessons learned from the former SSF Endrea (1997-ca. 2002, research on engineering design) and the ProViking (2002-2012, research on product realization) (ProViking, 2013) graduate schools. Both graduate schools were introduced together within research programmes with some similarities to the NFFP. Especially the Endrea $\mathrm{PhD}$ academy was successful with many former $\mathrm{PhD}$ candidates nowadays in leading academic and industrial positions within engineering design. Quality assessment (and assurance) was performed by a scientific advisory board of international experts within the field of study, who reviewed each student's research performance (and relevance) once a year. A positive side effect of this advisory board was not only to ensure high quality among the students but it also brought the spotlight to bear on the supervising professors. Additional quality assurance arrangements were implemented, following the graduate school quality assessment criteria and recommendations stated by the Swedish National Agency for Higher Education (Hogskoleverket, 2008). In addition to metrics for course/programme evaluation, this also includes the candidate recruitment process, the quality of the doctoral thesis, the individual researcher competence achieved (e.g. self-reliance), gender equality, international relations and support for mobility/travelling.

In addition to the education of PhD students, another important success factors had been common publications among the students (from different fields). An important lesson learned from the Endrea/Pro Viking graduate programmes is that there is an optimum number of school activities to avoid distraction and too high workload.

Too frequent activities distract the $\mathrm{PhD}$ candidates from their research and may result in too high workloads, whereas too few activities fall short as regards their feeling associated with the graduate school and do not lead to a sound research network among the students (e.g. evaluable through the number of collaborative publications). A fine balance between credit-giving courses, social activities/networking, quality assessment and aligned feedback is necessary. The planned types of courses within the SARC PhD academy can be classified as follows ${ }^{5}$ :

i. Shared soft skills courses (such as academic writing, research methods, research ethics, media training, etc.)

${ }^{5}$ For examples of such a course setup, see the ProViking course programme (ProViking, 2012). 
ii. Common basic/fundamental courses, creating a common sense and understanding among the students (within aeronautics e.g. aircraft design)

iii. Specialist courses close to the topics of the $\mathrm{PhD}$ candidates' research field(s).

At Endrea -- and similar planned for SARC -- courses were mainly given by members/professors of the contributing universities and research organizations. In addition, renowned international experts were invited to hold courses. The latter has two positive side effects: firstly ensuring a high-level education programme with attractive courses and secondly encouraging the establishment of links and networks between lecturers, students and the involved staff at the universities. This could (and should!) result in new collaboration and research programme applications.

\section{$\underline{\text { SARC's Future Education Ambitions }}$}

While the previous chapters are based on the analysis and explanation of facts and planned and founded SARC activities, the following section gives a future scenario and interpretation, based on the author's expected changes within universitybased education. So far, SARC's education activities focus solely on graduate students. This is a rather short-sighted approach with the well-aligned academia-industry interplay at hand (cf. Figure 1). To be well prepared for future scenarios, SARC is considering extending its activities into two additional topics: undergraduate education and work/job-accompanying courses. Several trends and possible game-changers may strongly influence and change higher education in the future:

- Trends within industry and the whole of society towards life-long learning

- Higher university graduation rate alongside a change in students' learning attitude

- Maturation of Information and Communication Technologies (ICT) and availability of Digital Teaching Tools (DTT) along with worldwide web access

- Internationalization and consequently a widespread availability of English education (material)

- Increased demand for shorter education programmes

It has to be highlighted that the above mentioned topics should not be interpreted as threads by universities, but as chance and possible game-changers for future academic education profiles. There will be a rising demand for short/block courses, perhaps partly or totally remotely given via the Internet, or as $24 / 7$ available material like e.g. the edX platform founded by MIT (edX, 2018). The European Bologna Bachelor-Master reform (Bologna reform, 1999, in Sweden established since 2007) -- driven by industrial needs -- paved the way for shorter educational (Bachelor and Master) programmes which replaced the usual five-year national university education degree (Swedish: civilingenjör), comparable with a Master certificate. 
In engineering education in particular, tremendous enhancements and cost/effort optimizations can be made possible e.g. by virtual labs (Bubhu, 2002) or Virtual Reality (VR) technology instead of hardware components and physical test benches. The availability of high-quality online courses -- partly offered free-of-charge and from high-ranked universities -- may change the education and certification system dramatically in the future (see e.g. the edX platform founded by MIT (edX, 2018)). Will traditional university education, especially at smaller universities, survive? Should academia in future open up for non-academic education programmes or courses and act more as an educational think-tank where interested people/students can stay for shorter periods and then return directly to their affiliation? From the SARC stakeholders' viewpoints, with the goal of strengthening national aeronautical education and industry, collaboration on undergraduate and extension studies for persons with work experience should be established in the future. While the author has no idea how this will look, inspiration can be taken from the research side. Given Sweden's limited size, research focus and competence are -- as explained in Section 3.2 -- already split into strategic collaborations between industry and universities with the help of the cluster leads. As an example, the aeronautical research focus at the three largest academic actors, KTH, LiU, and Chalmers, is related to certain competence domains (shown in Table 2). Consequently, would it not be possible to form a national aeronautical master education programme where every actor contributes its main competence? With the tight industry-academia coupling at hand, namely with the OEMs GKN in Gothenburg and Saab in Linköping, Sweden has the chance to shape a national aeronautical education programme (probably including practical internships) of a unique kind with a never before seen attraction that could beat top-ranked universities and attract students from all over the world to study aeronautics in Sweden.

Table 2 Overview of strategic industry-university collaboration fields within aeronautics.

\begin{tabular}{cl}
\hline \hline University & Main/Strategic Competence Domain \\
\hline KTH & Aerodynamics, CFD and Structure \\
\hline LiU & Aircraft Design and Control \\
\hline Chalmers & Propulsion System and Material \\
\hline \hline
\end{tabular}

\section{International Collaborations and Strategic Partner Countries}

The globalization and consolidation of the aviation market is also affecting Sweden. With the limited population size at hand, acting as an export-oriented nation, international relations are natural for independent Sweden. While not being part of NATO, close collaboration within aeronautics has been established since WW2 and the Cold War with central Europe, the UK and the United States. Since signing a large export contract for the Gripen aircraft with Brazil, a significant knowledge 
transfer and strategic collaboration with Brazil -- both on academia and industry level -- are being established, e.g. through the bilateral SWE DEMO project (VINNOVA, 2015).

Referring to the TRL-based slanted technology wave (see Figure 2) and the arguments in Chapter 2, demonstrator programmes are of a bi- or multi-lateral nature to handle the high complexity, size, and costs. Recent examples with Swedish industrial participation include the BLADE project (Airbus, 2017) and the UCAV/nEURON programme, both with a significant contribution from Saab. While the main Swedish aeronautical OEMs are large enough to apply for such large and complex long-term projects, most of the academia actors are not large enough to do so. SARC's ambition here is to form larger national alliances among the academia actors with significant expertise and size that are able to apply for larger EU-funded calls like the Clean Sky 2 (Horizon 2020) programme.

\section{CONCLUSION}

A national centre for research and education has been established in Sweden. The main motives are to promote long-term competence development and to strengthen aviation technologies (VINNOVA, 2018), one of the 17 strategic innovation programmes in Sweden (see (VINNOVA, 2018-2)). Focusing on the academic part within the overall socio-economic and R\&D interplay, SARC represents a long-awaited missing link towards the strategic (industrial) research clusters established about five years ago. With SARC in place, beneficial Triple-Helix effects are also expected through a stronger aeronautics policy influencing weight by this joint researcher forum.

While the TRL index is extensively used to plan, organize and review actions by INNOVAIR, it has been shown (in Chapter 2) that a more distinct approach using system-specific and system-integration related indices should be preferred to enable a more concise planning and arrangement between the academia researcher's and the industry's R\&D viewpoints. This is in particular the case when shifting the focus from complex product development towards SoS engineering. In this respect, SARC limits its own funded research to low-level TRLs only.

What is expected of SARC is to foster collaboration between all actors, enhancing the efficiency and coordination of research projects. SARC's own financing is limited; the major part will be used to drive the PhD school, e.g. finance courses and award scholarships or travel grants for the PhD students. A small part of the money can be used to finance long-term low-level research, e.g. to support important societal topics such as energy saving and environmental pollution, backing the European Commission's air mobility Flightpath 2015 agenda (ACARE, 2011). The first funded research project will be a joint $\mathrm{PhD}$ student research project to lay the foundation for assessing the environmental impact of technologies applied in the civil air transportation sector. Backed with domain-specific courses, this should result in interdisciplinary publications and widen the (researchers') horizon of the involved PhD students. 
SARC's financing is secured for the next 3 years only. Further continuation will only be possible if a new funder is found by

2021. The continuation will largely depend on whether SARC manages to form a joint national entity (without leaving any aeronautical research actor outside) and whether the stated goals are reached and can withstand a detailed assessment after that timeframe. However, first impressions and the feedback from both Swedish and international (Brazilian) researchers are positive and give hope for a long-lasting SARC.

\section{Acknowledgments}

The author would like to give credits to the founder and driving persons of the SARC initiative, namely Anders Blom (Director INNOVAIR), Prof. Dan Henningson (KTH), Prof. Petter Krus (LiU) and Prof. Tomas Grönstedt (Chalmers).

\section{References}

ACARE (2011), Flightpath 2050 - Europe's Vision for Aviation: Report of the High Level Group on Aviation Research, Advisory Council for Aviation Research and innovation in Europe (ACARE), European Commission, Doi 10.2777/50266 EUR 098 EN.

AIRBUS (2017), "BLADE press backgrounder: The breakthrough laminar aircraft demonstrator in Europe", technical report, Airbus, September 2017.

Alfredson, J. and Jouannet, C. (2017), "Saab - en klusterledares funktion och uppgifter", presented at the Seminarium för utlysning av NFFP7, INNOVAIR.

Blom, A. (2018), "INNOVAIRs SARC vision", presented at the SARC Kickoff Workshop, Linköping, 6 June 2018, Swedish Aeronautical Research Center, LiU.

Budhu, B. (2002), "Virtual Laboratories for Engineering Education", Proceedings of the International Conference on Engineering Education, International Network for Engineering Education and Research (iNEER), Manchester, UK.

edX (2018), edX: The online learning destination and MOOC, available at https://www.edx.org/learn/education (accessed 6 July 2018).

Eliasson, G. (2010). Advanced Public Procurement as Industrial Policy: The Aircraft Industry as a Technical University, Springer New York.

Etzkowitz, H. (2008), The Triple Helix: University-industry-government innovation in action, Routledge,New York and London.

Fung, D., Besters-Dilger, J. and Van der Vaart, R. (2017), "Excellent Education in Research-rich Universities", League of European Research Universities (LERU).

GAO (2016), "Technology readiness assessment guide”, GAO Reports GAO-16-410G, U.S. Government, Accountability Office (GAO).

Hartley, K. (2014), The political economy of aerospace industries: a key driver of growth and international competitiveness, Eward Elgar Publishing Ltd.

Hogskoleverket (2008), "Utvärdering av 16 nationella forskarskolor", report 2008:16, The Swedish National Agency for Higher Education (Högskoleverket), ISSN 1400-948X 
INNOVAIR (2018), National aeronautical research programme for aeronautics (INNOVAIR): The swedish strategic innovation program, available at http://innovair.org/en// (acessed 29 June 2018).

Krus, P. (2018), "SARC.academy: National graduate school for aeronautics", presented at the SARC Kickoff Workshop, Linköping, 6 June 2018. Swedish Aeronautical Research Center, LiU.

Maier, M.W. (1998), "Architecting principles for systems-of-systems”, The Journal of Systems Engineering, Vol.1, Nr.4, pp.267-284.

NASA (2007), Systems engineering handbook, Nasa/sp-2007-6105 rev1, National Aeronautics and Space Administration (NASA), Washington D.C., U.S.

Naturvardsverket (2017), "Sweden's seventh national communication on climate change", technical report, Government Offices of Sweden, Ministry of the Environment and Energy (Naturvårdsverket), ISSN 0282-7298.

NFFP (2018), NFFP - the swedish national aeronautical research program, available at: https://innovair.org/internationella-forskningsprogram/nffp/ (accessed 29 June 2018).

Olsson, M.-O. (2018), "NFFP: The swedish national aeronautical research program", presented at the SARC Kickoff Workshop, Linköping, 6 June 2018. Swedish Aeronautical Research Center, LiU.

ProViking (2012), ProViking course program. http://www.chalmers.se/ppd/provikingforskarskola-sv/kursprogram (accessed 2 July 2018).

ProViking (2013), ProViking - en satsning på svensk industri, available at http://innovair.org/en// (accessed 2 July 2018).

SARC (2018), The swedish aeronautical research center (SARC), available at: http://www.sarc.center/ (accessed 29 June 2018).

Sauser, B., Raminez-Marquez, J., Verma, D. and Gove, R. (2006), "From TRL to SRL: the concept of systems readiness levels", in Conference on Systems Engineering Research 2006, INCOSE, Los Angeles, USA.

Sauser, B., Forbes, E., Long, M. and McGrory, S.E. (2009), "Defining an integration readiness level for defense acquisition", in International Symposium of the International Council on Systems, INCOSE.

Staack, I., Amadori, C., Jouannet, C. (2018), "A holistic engineering approach for aeronautical product development", 31st Congress of the International Council of the Aeronautical Sciences, September 9-14 2018, ICAS, Belo Horizonte, Brazil.

Tillvaxtanalys (2016), "Nurturing spillover from the industrial partnership between Sweden and Brazil: a case study of the Gripen project", technical report, The Swedish Agency for Growth Policy Analysis (Tillväxtanalys), Östersund, Sweden.

Vallhagen, J. (2016), "Tekniska kluster- lessons learned", In Innovais årsmöte, Trollhättan, September 2016.

VINNOVA (2015). "SWE DEMO utlysning", Verket för Innovationssystem - Swedish Governmental Agency for Innovation Systems.

VINNOVA (2018), "SARC projekt: Beslut om bidrag", technical report nr. 2018-00063, Verket för Innovationssystem Swedish Governmental Agency for Innovation Systems.

VINNOVA (2018-2), The strategic innovation programmes, VINNOVA: Verket för Innovationssystem- Swedish Governmental Agency for Innovation Systems, available at https://www.vinnova.se/en/m/strategic-innovationprogrammes/ (accessed 3 July 2018).

Åström, T., Jansson, T., Mattsson, P., Segerpalm, H. and Faugert, S. (2008), "Evaluation of the Swedish national aeronautics research programme - NFFP", report VR 2008:05 2006-00665, VINNOVA - Verket för Innovationssystem. 